\title{
DEBATES ONLINE E SEU PAPEL DEMOCRÁTICO: uma análise das principais
} características e ferramentas

\section{ONLINE DEBATES AND ITS DEMOCRATIC ROLE: an analysis of the main characteristics and tools}

\author{
Rafael SIMONASSI ${ }^{1}$, Edilson FERNEDA ${ }^{2}$, Hércules Antonio do PRADO ${ }^{3}$, Luiza Beth \\ Nunes $\mathrm{ALONSO}^{4}$, Ricardo Spindola MARIZ ${ }^{5}$
}

Resumo: No passado, os debates eram realizados em ambientes organizados em um espaço onde a participação das pessoas necessitava da sua presença física. Com a Internet, e, principalmente, a Web 2.0, um novo contexto de comunicação surgiu e os debates, antes momentâneos, agora podem ser estendidos por um período mais longo, e seu ambiente pode ser ampliado além dos limites espaciais que antes o limitavam. Com as atuais tecnologias, é possível assumir a posição de interlocutor nas discussões por meio de projetos independentes, ou via coletivos ou associações que se servem das atuais ferramentas online disponíveis. É nesse contexto que o presente trabalho, realizado a partir de uma pesquisa documental, objetiva estabelecer uma discussão sobre as particularidades e o papel de ferramentas tecnológicas no incremento de debates democráticos. Neste artigo são discutidos os conceitos de debate, a sua contribuição para a democracia, sua evolução para os debates online e algumas das ferramentas disponíveis para isso.

Palavras-chave: Debates online. Web 2.0. Democracia. eDemocracia. Governo Participativo.

\footnotetext{
${ }^{1}$ Mestre em Gestão do Conhecimento e Tecnologia da Informação pela Universidade Católica de Brasília. E-mail: rafa.simonassi@gmail.com.

2 Professor do Mestrado em Gestão do Conhecimento e Tecnologia da Informação da Universidade Católica de Brasília, Mestre em Sistemas e Computação pela Universidade Federal de Campina Grande, Doutor em Computação pelo Laboratoire dInformatique, Robotique et de Microélectronique de Montpellier - LIRMM / Universidade de Montpellier II, França. E-mail: eferneda@pos.ucb.br.

${ }^{3}$ Professor do Mestrado em Gestão do Conhecimento e Tecnologia da Informação da Universidade Católica de Brasília, Mestre em Engenharia de Sistemas e Computação pela COPPE / Universidade Federal do Rio de Janeiro, Doutor em Ciências da Computação pela Universidade Federal do Rio Grande do Sul. E-mail: hercules@ucb.br

${ }^{4}$ Professora do Mestrado em Gestão do Conhecimento e Tecnologia da Informação da Universidade Católica de Brasília, Mestre e Doutora em Educação pela Universidade de Harvard. E-mail: lualonso@ pos.ucb.br.

${ }^{5}$ Professor do Mestrado em Gestão do Conhecimento e Tecnologia da Informação e do Programa de Pós-Graduação em Educação da Universidade Católica de Brasília, Mestre em educação e Doutor em Sociologia pela Universidade de Brasília. E-Mail: Spindola@ucb.br.
} 
Abstract: In the past, debates were carried out in organized environments where the participation of people used to require their physical presence. With the Internet and especially Web 2.0, a new communication context emerged and a debate, which used to be momentary, can now be extended for a longer period, and its environment can be extended beyond the spatial boundaries in which where they were restricted. With the current technology, it is possible to assume the position of interlocutor in discussions by means of independent projects, or via associations, that apply the current available online tools. In this context, the present study, done through a documental research, aims to establish a discussion on the characteristics and the role of technology of information tools for online democratic debates. This article presents concepts of debate, its contribution to democracy, its evolution to online debates and the main tools available to it.

Keywords: Online debates. Web 2.0. Democracy. eDemocracy. Participatory Government. 


\section{miDiA

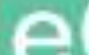 \\ DiAno}

\section{Introdução}

Desde a Grécia antiga, os debates já eram conhecidos e praticados pelo seu povo (OBER; HEDRICK, 1996, p. 20). Era por meio dos debates que temas relevantes podiam ser incluídos nas pautas de discussão, permitindo que a tomada de decisão pudesse ser mais participativa. Segundo Bidima (1997), o conceito de palabre indica que vários indivíduos, membros de uma sociedade, podiam expressar suas opiniões acerca de um determinado assunto, objetivando a chegada a um consenso. Diferentes atividades, como a expressão de opiniões e a formulação consensual são aquelas que circundam a principal finalidade do estabelecimento de um debate.

Atualmente, o tema da participação ganha uma nova importância. Por um lado, vivemos uma tendência de desgaste das formas tradicionais da ação coletiva que caminha para uma ruptura entre a política e o poder. "Nenhum dos movimentos sociopolíticos que ajudaram a minar as bases do velho mundo está pronto para herdá-lo" (BAUMAN; MAURO, 2016, contracapa). Por outro lado, vivemos um crescente de debates nas redes sociais, mas que quase sempre acontece, em função da própria dinâmica das redes, entre pares e pensamentos afins, não se configurando de fato em um debate.

A "ágora” como espaço privilegiado de encontro, debate e decisão política está em mutação. Para Bourdieu (1989), a própria política passa por um momento de esvaziamento do seu poder simbólico. Esse esvaziamento convive, de maneira paradoxal, com um momento de muito "debate" na sociedade, na verdade um momento de muita expressão de opiniões (doxa). Dessa forma, os espaços coletivos, físicos ou virtuais, não têm sido espaços de aprofundamento de posições, mas de consolidação do reino da doxa.

De outra forma, abrir mão do espaço coletivo de decisão é reforçar uma tendência da "tirania da intimidade". Tendência percebida há quase duas décadas por Sennett (1999), a partir de seus estudos sobre o declínio do homem público. Essa tendência pode ser invertida pelo resgate dos fundamentos e da importância do debate na construção de solução dos impasses, agregado por novas possibilidades da tecnologia para sua formatação. 


\section{míDiA

Enquanto no passado os debates eram organizados em um único espaço e a participação das pessoas era realizada pela sua presença física, na atualidade, com a evolução dos meios de comunicação para a atual Internet, e, principalmente, após a inovação trazida pela Web 2.0, os debates ganharam um novo contexto. Os debates, antes momentâneos, agora podem ser estendidos por períodos mais longos, e o ambiente necessário para ele pode ser ampliado além dos limites espaciais antes utilizados. Os debates 2.0 (nome dado pela junção de debates e Web 2.0, ora chamado de debates online) surgiram dos novos meios de comunicação e são dedicados principalmente à concertação de pessoas que visa obter a opinião dos cidadãos sobre determinados assuntos (ALBRECHT, 2006).

O termo debate, por si só, é geralmente associado apenas às concertações originadas por gestores ou tomadores de decisões políticas sem a participação significativa dos cidadãos. Aqueles que desejam ter participação ativa no processo de tomada de decisão coletiva em uma democracia representativa possuem poucas ou nenhuma oportunidade de expressarem seus anseios nos debates políticos. No entanto, com o surgimento da Web 2.0, parece haver uma forte tendência de alteração desse cenário. Agora, o público pode deixar de ser um agente paciente e passivo para ocupar o papel de interlocutor nas discussões. Isso pode se dar por meio de projetos independentes, coletivos ou associações que se servem das atuais ferramentas online disponíveis.

Neste artigo são apresentados os principais conceitos de debate, a sua contribuição à democracia, a evolução para os debates online e algumas das ferramentas já existentes. A análise dessas ferramentas é também realizada com a intenção de contribuir para que o leitor compreenda as principais características esperadas de uma ferramenta de debates online. Por fim, são apresentadas as conclusões e sugeridas funcionalidades que poderiam ser incorporadas ao contexto.

\section{Debate como conceito}

O debate é estudado e praticado desde o surgimento da democracia na Grécia no século V a.C. (OBER; HEDRICK, 1996, p. 20). Ele é um meio adotado para permitir que todos possam participar dos processos de tomada de decisão. Por meio do debate, a 
palavra é dada às pessoas que, segundo Bidima (1997) e seu conceito de palabre, é o meio pelo qual se permite a vários indivíduos dentro de uma sociedade expressar suas opiniões para chegar a um consenso. Essas atividades, expressão de opiniões e formulação consensual, são aquelas que circundam a principal finalidade do estabelecimento de um debate. Seilles (2012) apresenta os seguintes pontos que considera como as principais características de um debate:

* Um debate é um lugar de exposição de argumentos para formar uma argumentação. O argumento, por sua vez, é uma parte da discussão em que se apoia ou se opõe a uma opinião (CHABROL; BROMBERG, 1999). Portanto, o argumento é intrínseco do indivíduo e complementado com diferentes opiniões. $\mathrm{O}$ conjunto de argumentos se transforma naquilo que pode ser chamado de argumentação. Uma argumentação, por fim, utiliza o debate como um local de sua exposição e tem por objetivo abarcar os pontos favoráveis e desfavoráveis até que eles sejam acordados ou refutados entre os participantes;

* Um debate é composto, em sua essência, de partes envolvidas (stakeholders ou cidadãos). As partes envolvidas são os atores participantes no processo decisório ao qual um debate pode estar sujeito. Por exemplo, caso os debates sejam considerados públicos, o objetivo é permitir que os tomadores de decisão possam ser receptivos à contribuição dos cidadãos. Os stakeholders são os indivíduos ou grupos de indivíduos que serão afetados por essa decisão;

* Um debate deve centralizar as discussões. Fazendo uma analogia ao que já existe na Internet, um debate incorpora a capacidade de discussão de fóruns e blogs em um único lugar de acesso;

* Um debate deve ser capaz de sintetizar seu conteúdo. Cada debate apresenta um conjunto de informações que podem ser sintetizadas em torno de argumentos. Essas sínteses podem ser usadas para suportar a comunicação entre os participantes de um debate;

* Um debate deve permitir a expressão de opiniões. Esse é um requisito mínimo, para que um debate seja conduzido de forma democrática; 
* Os cidadãos devem ser capazes de se identificar. Não se trata de uma obrigatoriedade, mas a auto-identificação dos participantes deve ser facultada a cada um.

Dois outros conceitos relevantes são a concertação e os debates em grande escala. Concertação é a atividade pela qual se obtém uma visão geral das opiniões dos cidadãos sobre um ou mais assuntos. Os debates são, portanto, uma tentativa de realizar a concertação ao introduzir a participação ativa dos cidadãos. Os debates em grande escala, por sua vez, são as ações que permitem que um vasto número de interessados participe de uma concertação. Um debate na escala de uma coletividade territorial é considerado um debate em grande escala. Esse tipo de debate envolve, necessariamente, um grande número de informações produzidas por e para seus participantes. Assim, durante sua existência, deve ser dada a oportunidade aos cidadãos de se expressarem sobre os assuntos e, também, participarem da construção de julgamentos coletivos.

Quanto à representatividade dos julgamentos produzidos por debates em grande escala, o seu impacto real deve pesar sobre as decisões políticas, garantindo um viés democrático aos participantes. Para o fortalecimento da democracia, percebe-se que um debate deve ser de acesso irrestrito. À medida que a quantidade de participantes envolvidos aumenta, o volume de informações produzidas cresce, conduzindo a uma maior representação democrática no cerne das discussões.

Expostas as características dos debates e com o intuito de nortear o foco do estudo, entende-se, nesse trabalho, o debate como um centro de concertação de cidadãos que buscam a apresentação de argumentos em torno de um tema específico e cujos envolvimentos englobam a expressão de opiniões e a sintetização de conteúdo, visando uma contribuição democrática ampliada, na medida em que sua escala se amplia.

\section{Contribuição social dos debates}

Os debates surgiram como uma forma de auxiliar a participação da população nas decisões democráticas. Sua principal relevância foi permitir a participação do indivíduo na esfera coletiva. Consideremos três tipos simplificados de governo em uma sociedade: monarquia, oligarquia e democracia (WALL, 1993). Na monarquia o seu centro é caracterizado pela aristocracia, onde todos os poderes e pensamentos são concentrados 
em uma personalidade única: o monarca. Se o monarca é substituído por um pequeno grupo de pessoas, tem-se o que se chama de oligarquia. Ditaduras têm características que as aproximam de algumas monarquias e oligarquias. A democracia, por sua vez, é exatamente o oposto da monarquia, significando literalmente que todos são participantes das decisões.

Mas como garantir a participação das pessoas visando fortalecer o cunho democrático é uma questão, no mínimo, desafiadora. Segundo Bordenave (1983, p. 11), a participação é algo intrínseco ao ser humano. As pessoas participam em sua família, em sua comunidade, no trabalho e no embate político. Ainda segundo esse autor, nenhum ser humano é uma ilha e o maior erro das ditaduras é pensar que toda a população se sente aliviada por não ter que tomar decisões, preferindo transferi-las ao governo.

Mas a maioria prefere a democracia. E para um crescente número de pessoas, democracia não é apenas um método de governo onde existem eleições. Para elas, democracia é um estado de espírito e um modo de relacionamento entre as pessoas. Democracia é um estado de participação (BORDENAVE, 1983, p.8).

No ordenamento jurídico brasileiro, há diversas formas de exercer essa participação democrática (PAULO; ALEXANDRINO, 2011, p. 267): (i) direito ao sufrágio, que é materializado no direito de votar e ser votado; (ii) direito ao voto nas eleições, plebiscitos e referendos e (iii) direito à iniciativa popular de lei, que é a capacidade do cidadão propor leis.

Embora haja um caráter normativo das formas participativas acima descritas, o mundo está evoluindo para fortalecer a participação do cidadão de forma mais efetiva (KLEBA; WENDAUSEN, 2009). Os setores progressistas, que desejam uma democracia mais autêntica, são seus grandes promotores (BORDENAVE, 1983, p. 12). Sob o ponto de vista desses setores, a participação facilita o crescimento da consciência crítica da população e fortalece seu poder de reivindicação. E é nesse contexto que surge a eDemocracia. Com o advento das Tecnologias da Informação e Comunicação (TICs), a sociedade possui novas ferramentas para interação, incluindo sua participação em processos decisórios. Ou seja, a possibilidade de concertação dos participantes de um processo decisório democrático pode ser ampliada com a introdução das TICs. 


\section{míDiA

Uma das expectativas da eDemocracia é aumentar o âmbito da concertação e garantir a transparência dos sistemas administrativos e políticos, dando ao público o seu lugar nos debates. A Internet torna-se, assim, um canal de comunicação e vem naturalmente substituir seus antecessores (por exemplo, o telégrafo, o rádio, a televisão e o telefone) no campo ainda experimental da eDemocracia. Embora o início da eDemocracia seja anterior à Internet, ela se amplia ainda mais com o uso das TICs. A Internet, mais especificamente a Web, tornou-se $\mathrm{o}$ terreno de predileção das experiências do domínio participativo. As aplicações Web para a eDemocracia podem cobrir todas as etapas da tomada de decisão, desde a concertação até o voto. A eDemocracia pode ainda ser subdividida em vários domínios, sendo os debates um deles. Assim, uma ferramenta de concertação para auxiliar a participação dos cidadãos, ou o debate 2.0, como a chama Seilles (2012), é uma contribuição significativa que amplia o alcance democrático da sociedade.

\section{Debates 2.0}

Em sua definição de debates 2.0, Seilles (2012) une os conceitos de Web 2.0 e de debates. $\mathrm{O}$ que diferencia a Web 2.0 da que a antecede é principalmente o fato de que o conteúdo das páginas naquela é gerado pelo usuário (O 'REILLEY, 2007). Antes da Web 2.0, a Internet era provida de um conjunto de páginas estáticas, escrito por uma pessoa e acessível a todos os outros, mas somente para leitura. Com a chegada, em 1995, dos primeiros Wikis e fóruns, torna-se possível não só ler páginas, mas modificá-las, editálas, comentá-las e completá-las.

É importante frisar essa nova fase da Internet, pois, antes, os grupos difusores eram privilegiados em detrimento da comunicação entre as pessoas. A Internet pré-Web 2.0 era, assim como os meios de comunicação predecessores, uma mera difusora de informações, ou seja, a comunicação se realizava em um só sentido (da mídia para os consumidores das informações). Ela era apenas uma continuação das quatro revoluções dos meios de comunicação que apareceram nos últimos 500 anos: imprensa, telégrafo, rádio e televisão (SHIRKY, 2009). Com o advento da Web 2.0, houve o fortalecimento do capital social, a valorização do indivíduo e a contribuição coletiva. Esse novo conceito permitiu que as pessoas pudessem apoiar ideias e terem suas próprias ideias 
suportadas por outros, contribuindo para a ampliação de uma comunidade social ubíqua e global.

Atualmente, as diversas aplicações da Web baseiam-se no conceito de edição ou criação coletiva de conteúdo. Wikis permitem que um grupo de usuários coescrevam uma página. Fóruns fornecem a possibilidade de um grupo de usuários deixarem mensagens para construir uma discussão. Blogs deixam que qualquer pessoa crie uma página e que outros coloquem seus comentários. Sítios de música fornecem aos usuários a possibilidade de opinião sobre as músicas. Os sítios de varejo permitem opinar sobre um produto comprado ou sobre a qualidade do serviço prestado. Nas redes sociais, é possível, em qualquer página, dizer se você gosta dela clicando no botão "Curti”, como no Facebook. Nesse contexto de colaboração, alguns já dizem que o usuário não é um mero consumidor, mas também um ator informacional, já que ao consumir de forma consciente, ou como falam os franceses, um "consommacteur" (ou "consom'acteur"), ele também consome e produz informações (CAILLET; COMTESSE, 2008). De forma mais geral, Cachinho (2006) refere-se, em português, a "consumactor", aquele que consume (gasta e investe) com ética, e Cogoy (1999) discorre sobre o consumidor como agente social e ambiental.

Os exemplos citados testemunham a prática do conceito de Web 2.0 por meio do qual a qualidade dos serviços pode melhorar pela interação. Em outras palavras, o usuário de um serviço cria, pelo uso, novos dados que são fundamentais para a melhoria do serviço. Por exemplo, sistemas de recomendação para as vendas online analisam o histórico de compras e traços de uso para recomendar outras compras pertinentes.

Nessa junção de consumidor e ator, o debate 2.0 surge como uma ferramenta da Web 2.0 onde os participantes consomem e atuam produzindo mais informações. Os debates 2.0 são dedicados principalmente à concertação que visa obter a opinião dos cidadãos sobre determinados assuntos. Cabe observar que o termo debate, por si só, é geralmente associado apenas às concertações originadas por gestores ou decisores políticos e é raramente associado aos anseios dos cidadãos que desejam participar ativamente do processo por meio de uma tomada de decisão coletiva. Entretanto, com a evolução para a Web 2.0, parece haver uma forte tendência do público em relação a esse cenário. 


\section{midiA
eCOti
DiAno}

Objetivando promover debates democráticos na Web, Seilles (2012) propôs um modelo de ambiente Web de debates 2.0, batizada de Argumentea. Seu principal propósito era apoiar a gestão de interações de cidadãos existentes nas zonas costeiras de diferentes regiões. Essas interações permitiriam uma ampliação do debate participativo e seu trabalho focou na concepção e desenvolvimento de ferramentas de apoio à concertação, promoção de debates, promoção de escrita colaborativa e criação de uma ligação funcional entre os cidadãos, gestores e líderes. De cunho democrático, Argumentea incorpora algumas funcionalidades da Web 2.0 que são essenciais para permitir a participação dos cidadãos. Entre essas funcionalidades destaca-se a capacidade de anotação, expressão de opiniões e discussão sobre os pontos de vista externados.

A anotação, já bastante utilizada na Web, possui como principal característica a capacidade de ampliar a comunicação e a colaboração escrita. Argumentea considera a anotação como ponto de partida para a interação dos participantes do debate. Seilles (2012) cita dois tipos básicos de anotação: a discursiva e a semântica. A primeira diz respeito à prática interativa semelhante à postagem de opiniões dos fóruns ou blogs. Esse tipo de anotação permite aos usuários expressar suas opiniões sobre trechos e frases de outros participantes. A anotação semântica, por sua vez, refere-se ao uso de tecnologias da Web Semântica. Trata-se de tornar explícita a informação concernente a um documento ou a um trecho dele. Essas informações, chamadas de metadados, são adicionadas através das anotações semânticas, a fim de explicitar, para um sistema computacional, as informações sobre o contexto de produção. Por exemplo, as anotações semânticas podem especificar quem é o autor do documento, em que data ele foi produzido e os temas abordados. Seilles usa ambos os tipos de anotação como uma solução de estruturação de debates, permitindo que diferentes pontos de vistas sejam colocados sobre um ou mais argumentos construídos pelos participantes.

A Figura 1 ilustra um substrato de um debate realizado na ferramenta Dialoguea, uma implementação do modelo Argumentea. A partir de um texto sobre o qual se irá debater, um participante [A], em certo momento [D], seleciona uma parte do texto motivador $[\mathrm{T}]$ e inclui um comentário $[\mathrm{C}]$ na forma de anotação, que reforça (cor azul) 
ou contradiz (cor vermelha) o texto original. Cada anotação pode, por sua vez, ser comentada pelos demais participantes do debate.

Pode haver aí regulação por auto-organização dos debates, pois se trata de manter um equilíbrio entre a identificação/certificação e promover a liberdade de expressão...?

A: [Participante 4]

D: 14/08/2015, às 19:43

T: "regulacão por auto-organizacão dos debates"

C: A regulação deve vir "de baixo" para estar em conformidade com o modelo de uma democracia participativa.

A: [Participante 1]

D: $15 / 08 / 2015$, às $11: 26$

T: "A regulação deve vir "de baixo" para estar em conformidade com o modelo de uma democracia participativa."

C: Eu não estou totalmente de acordo. Se se multiplica por milhares os debates, como a lei impõe, é preciso que sua certificação seja tão banal quanto um envelope selado.

\section{A: [Participante 1]}

D: 15/08/2015, às 11:39

T: "auto-organização dos debates"

C: É preciso uma parte de autorregulação propícia à liberdade que pode ser garantida por uma regulação superior de defesa da ética.

A: [Participante 3]

D: 15/08/2015, às 21:07

T: "uma regulação superior de defesa da ética"

C: Necessidade de moderadores, de representantes e de um conselho dos representantes.

Figura 1: Substrato de um debate realizado com o uso da ferramenta Dialoguea

\section{Onde se situam os debates online?}

Em uma primeira aproximação do conceito de debates online, é possível confundi-lo com um blog, fórum ou outras ferramentas de interação online (chats, por exemplo). Entretanto, à medida que se analisa a definição dessas ferramentas, é possível traçar um contexto distinto ao qual o debate online se encontra. Para melhor compreender a diferença que o destaca, é necessário analisar o conceito das outras ferramentas.

A primeira delas, o blog, se conceitua como uma ferramenta de comunicação entre particulares, em que um usuário expõe suas ideias sobre determinados textos, vídeos ou outras mídias apresentadas. Sobre eles, um usuário pode exprimir sua posição por meio daquilo que foi chamado de postagem (post) (SEILLES, 2012). Estas 
postagens são apresentadas de forma cronológica e tratam sobre o tópico inicialmente abordado. Por meio dos blogs, conhecimentos e reflexões podem ser compartilhados, podendo atrair diferentes tipos de leitores (BOULOS; MARAMBA; WHEELER, 2006). A principal diferença entre um blog e um fórum online reside na ideia de que o primeiro apresenta um autor/criador do tópico debatido colocando-o à frente de seus leitores, enquanto que no segundo não há a distinção entre autores e leitores. Consideramos debate online como uma ferramenta que favorece a expressão de uma posição a favor ou contra (opinião). Sendo que a principal diferença de um debate online para com um blog ou fórum online reside na capacidade de centralizar essas posições com o intuito de democratizar uma discussão, uma vez que esses últimos não têm como objetivo tal atividade.

Outro tipo de ferramenta colaborativa bastante conhecida são os chamados sítios Wikis, cujo conteúdo informativo e de uso coletivo é usado como fonte de conhecimento e pode ser editado por qualquer um que tenha acesso a ele (BOULOS; MARAMBA; WHEELER, 2006). Conceito inicialmente apresentado por Howard G. "Ward" Cunningham em 1995, talvez o melhor exemplo de Wiki seja a popular Wikipedia. Esta se caracteriza como fonte de obtenção de informações e conhecimento, e também um método colaborativo para compartilhá-los entre seus participantes. Essas ferramentas permitem que um conjunto de páginas seja criado, editado e difundido em tempo real. E, embora argumentos e posições possam ser colocados quando estamos tratando de determinados assuntos, os Wikis não têm como objetivo o debate coletivo. Eles focam na criação de conteúdo e sua principal diferença para com os debates online, tal como os blogs e fóruns, repousa na ideia de que os debates focam justamente na concertação de argumentos.

Pode-se ainda fazer uma comparação com os sítios de redes sociais. Reconhecidamente surgidas no ano de 1997, as redes sociais são definidas como serviços Web que permitem aos indivíduos: (i) construir um perfil público ou semipúblico; (ii) articular uma lista de usuários com as quais eles se conectam; e (iii) viabilizar a permutação destas de tal modo que um usuário possa conhecer as listas de conexão de outro (BOYD; ELLISON, 2007). MySpace, Orkut, Mixi e Facebook são apenas alguns exemplos de redes sociais. E, embora todas elas permitam a expressão de 


\section{PPGMC}

\section{DiAno}

opiniões sobre uma postagem, seus objetivos não compreendem a arguição e a concertação de pessoas interessadas em determinados assuntos, que acreditamos ser o cerne conceitual de um debate online.

Percebe-se, portanto, que o foco na argumentação e sua concertação são as características dos debates online que os diferenciam dos demais. Outras ferramentas de interação Web poderiam ser ainda citadas, mas não é intenção deste trabalho esgotar todas as possíveis comparações com os debates online. Procura-se tão somente qualificar o espaço no qual os debates online se encontram e, para isso, buscou-se ilustrar o papel de algumas ferramentas já consolidadas no ambiente Web.

Algumas das ferramentas atualmente conhecidas e utilizadas para a construção dos debates online são avaliadas no Quadro 1 segundo as seguintes características:

Quadro 1: Ferramentas de debates online

\begin{tabular}{l|c|c|c|c|c}
\hline \multicolumn{1}{c|}{$\begin{array}{c}\text { Nome / } \\
\text { Endereço eletrônico }\end{array}$} & $\begin{array}{c}\text { Posições a } \\
\text { favorou } \\
\text { contrárias }\end{array}$ & Textos livres & $\begin{array}{c}\text { Texto } \\
\text { motivador } \\
\text { introdutório }\end{array}$ & $\begin{array}{c}\text { Argumento } \\
\text { hierárquico }\end{array}$ & Anotação \\
\hline $\begin{array}{l}\text { Convinceme / } \\
\text { www.convinceme.net }\end{array}$ & $\bullet$ & $\bullet$ & & & \\
\hline $\begin{array}{l}\text { Createdebate / } \\
\text { www.createdebate.com }\end{array}$ & $\bullet$ & $\bullet$ & $\bullet$ & & \\
\hline $\begin{array}{l}\text { Debate.org / } \\
\text { www.debate.org }\end{array}$ & $\bullet$ & $\bullet$ & $\bullet$ & & \\
\hline $\begin{array}{l}\text { Debatepedia / } \\
\text { www.debatepedia.com }\end{array}$ & $\bullet$ & $\bullet$ & $\bullet$ & & $\bullet$ \\
\hline $\begin{array}{l}\text { Dialoguea / } \\
\text { www.dialoguea.fr/\#/ }\end{array}$ & $\bullet$ & $\bullet$ & $\bullet$ & $\bullet$ & $\bullet$ \\
\hline $\begin{array}{l}\text { ForandAgainst / } \\
\text { www.forandagainst.com }\end{array}$ & $\bullet$ & $\bullet$ & $\bullet$ & $\bullet$ & \\
\hline $\begin{array}{l}\text { Idebate / } \\
\text { www.idebate.org }\end{array}$ & $\bullet$ & $\bullet$ & $\bullet$ & & \\
\hline $\begin{array}{l}\text { onlineDebate / } \\
\text { www.onlinedebate.net }\end{array}$ & $\bullet$ & $\bullet$ & & & \\
\hline $\begin{array}{l}\text { Takeonit / } \\
\text { www.takeonit.com }\end{array}$ & & $\bullet$ & & & \\
\hline
\end{tabular}

* Qualificação das posições como concordantes ou discordantes: considera-se que esta é uma das funcionalidades principais de uma ferramenta de debates online. É por meio dela que o cidadão pode opinar explicitamente a respeito do tema. Percebe-se que, curiosamente e apesar do nome, somente a ferramenta onlineDebate não inclui tal funcionalidade. Acreditamos que a ausência de tal 
funcionalidade equipara tal ferramenta a um fórum de discussão e não a um debate.

* Capacidade de expor textos livres: embora todas as ferramentas apresentadas incluam essa funcionalidade, consideramos relevante ressaltá-la. Caso tal funcionalidade não estivesse presente, as ferramentas não passariam de instrumentos de enquetes, onde perguntas seriam correspondidas por respostas restritas a uma lista fechada, por exemplo, 'Sim', 'Não' ou 'Talvez'. Isso impediria uma participação mais democrática do cidadão, que, por muitas vezes, quer contribuir com informações além daquelas contidas nas listas fechadas.

* Texto motivador introdutório: aquelas ferramentas que não permitem que um texto motivador seja apresentado geralmente permitem uma pergunta inicial. Tal pergunta tem como objetivo indagar a posição sobre determinado assunto. Não obstante, considerando quão uma pergunta possa ser provocativa o suficiente para estimular a expressão de opiniões, acreditamos que um texto introdutório permite melhor expor o tema a ser debatido, diferentemente de uma simples pergunta. Por meio do texto, os assuntos podem ser melhor abordados inicialmente, focando em pontos que devem ser debatidos e removendo questões não interessantes ao debate.

* Capacidade de argumentar de forma estruturada: argumentos podem ser apresentados sobre outros argumentos e não somente sobre o texto ou pergunta inicialmente apresentados. Embora considerada como uma característica simples de ser implementada, nem todas as ferramentas a possuem. Avaliamos tal característica como essencial para um debate online, pois permite que haja uma interação explícita entre os cidadãos.

* Capacidade de anotação: representa a capacidade de marcar e comentar partes de um texto ou de uma argumentação. Para o cidadão, essa capacidade permite que determinados assuntos sejam destacados e debatidos, contribuindo para o aprofundamento das discussões. 


\section{míDiA

Pelas funcionalidades analisadas, fica evidente que a ferramenta mais aderente às características acima expostas é Dialoguea, por ser a única que apresenta todas as características que se acredita serem essenciais para uma ferramenta de debates online.

\section{Conclusão}

Foram apresentados os principais conceitos dos debates, bem como a sua evolução para os debates 2.0. Adicionalmente, a relevância dos debates no contexto da eDemocracia foi discutida e, também, foram trazidos alguns dos conceitos envolvidos em um debate: lugar de exposição, partes envolvidas, centro de discussão, sintetização de conteúdo, expressão de opiniões e identificação.

Foram elencados um conjunto de características desejáveis para uma ferramenta de debates online: qualificação das posições, exposição de textos livres, texto motivador introdutório, argumentação estruturada e capacidade de anotação. Os resultados mostraram que nem todas as atuais ferramentas possuem tais características, não podendo ser caracterizadas como ferramenta de debate segundo o conceito aqui defendido.

Como este é um tema recente, muitas outras características poderiam ser propostas, como, por exemplo, ferramentas de sumarização de um debate. Nenhuma das ferramentas analisadas oferece funcionalidades que possibilitem criar um sumário voltado especificamente para esse debate. O sumário permitiria uma referência rápida do tema debatido e das principais posições até o momento colocadas. Outros esforços de pesquisa e desenvolvimento podem ser despendidos com o objetivo de possibilitar que um debate online reproduza com mais fidedignidade os debates em sentido amplo, de forma que os interlocutores possam interagir de forma mais natural durante a exposição e discussão de seus argumentos. Acredita-se que, por intermédio de uma organização sistemática (seja pelo uso ou não de anotações), esses debates podem vir a ganhar maior visibilidade na comunidade da Internet e, por conseguinte, atingir maior amplitude democrática.

Consolidar novos caminhos que superem o impasse democrático que vivemos hoje é uma necessidade. Em uma sociedade que infelizmente ainda cresce em desigualdade e violência, o debate político e os arranjos coletivos precisam de 
aprimoramento. As soluções para nossos dilemas não está no isolamento das pessoas, seja por descrédito ou por medo dos espaços públicos carregados de violência. As saídas, mesmo que ainda nebulosas, serão construídas no encontro e no debate público.

\section{Referências}

ALBRECHT, S. Whose voice is heard in online deliberation?: A study of participation and representation in political debates on the internet. Information, Communication \& Society, v. 9, n. 1, p. 62-82, 2006.

BAUMAN, Z.; MAURO, E. Babel: entre a incerteza e a esperança. Rio de Janeiro: Zahar. 2016.

BIDIMA, J.-G. La Palabre: une juridiction de la parole. French Forum, v. 26, n. 3, p. 128-130, 2001.

BORDENAVE, J. E. D. O que é participação. São Paulo: Brasiliense, 1983.

BOULOS, M. N K.; MARAMBA, I.; WHEELER, S. Wikis, blogs and podcasts: a new generation of Web-based tools for virtual collaborative clinical practice and education. BMC Medical Education, v. 6, n. 41, 2006.

BOURDIEU, P. O poder simbólico. Rio de Janeiro : Editora Bertrand Brasil, 1989.

BOYD, D. M.; ELLISON, N. B. Social Network Sites: Definition, History, and Scholarship. Journal of Computer-me diated Communication, v. 13, n. 1, p. 210-230, 2007.

CACHINHO, H. Consumactor: da condição do indivíduo na cidade pós-moderna. Finisterra, v. 41, n. 81, 2006.

CAILLET, B.; COMTESSE, X. L'Intervention des territoires directs par les gens ordinaires. Genève: ThinkStudio, 2008.

COGOY, M. The consumer as a social and environmental actor. Ecological Economics, v. 28, n. 3, p. 385-398, 1999.

CHABROL, C.; BROMBERG. M. Préalables à une classification des actes de parole. Psychologie Française, v. 44, n. 4, p. 291-306, 1999.

KLEBA, M. E.; WENDAUSEN, A. Empoderamento: processo de fortalecimento dos sujeitos nos espaços de participação social e democratização política. Saúde e Sociedade, v. 18, n. 4, p. 733-743, 2009.

OBER, J.; HEDRICK, C. Demokratia: a conversation on democracies, Ancient and Modern. Princeton: Princeton University Press, 1996.

O'REILLEY, T. What Is Web 2.0: design patterns and business models for the next generation of software. Communications \& Strategies, n. 1, p. 17-37, 2007.

PAULO, V.; ALEXANDRINO, M. Direito constitucional descomplicado. 7. ed. São Paulo: Método, 2011.

SEILLES, A. Structuration de débats en ligne à l'aide d'annotations socio-sémantiques: vers une analyse de réseaux sociaux centrés sur l'interaction. 2012. $209 \mathrm{f}$. Tese [Doutorado em Ciência da Computação]. Laboratoire d'Informatique, Robotique et Microélectronique de Montpellier, Université Montpellier II, Montpellier, França: LIRMM-CNRS, 2012. 
SENNETT, R. O declínio do homem público: as tiranias da intimidade. São Paulo: Companhia das Letras, 1999.

SHIRKY. C. How social media can make history. 2009. (15 min.), son., color. Legendado. Disponível em: <http://www.ted.com/talks/clay_shirky_how_cellphones_twitter_facebook_ can_make_history>. Acesso em: 29 mar. 2016.

WALL, G. Exergy, ecology and democracy: concepts of a vital society or a proposal for an exergy tax. Proce edings of the International Conference on Energy Systems and Ecology, Krakow: Ensec, 1993. p. 111-121. 